\title{
Evaluation of interdental distance of natural teeth with cone-beam computerized tomography
}

\author{
Sang-Chun Oh' ${ }^{1 *}$, Hyun-Jun Kong', Wan Lee ${ }^{2}$ \\ 'Department of Prosthodontics, College of Dentistry, Wonkwang University, Iksan, Republic of Korea \\ ${ }^{2}$ Department of Oral and Maxillofacial Radiology, College of Dentistry, Wonkwang University, Iksan, Republic of Korea
}

Purpose: The aim of this study was to evaluate the interdental distances of anterior, premolar, and molar teeth at the cementoenamel junction (CEJ) and $2 \mathrm{~mm}$ below the CEJ in healthy natural dentition with cone-beam computerized tomography (cone-beam $\mathrm{CT}$ ) in order to provide valuable data for ideal implant positioning relative to mesiodistal bone dimensions. Materials and Methods: Two hundred patients who visited Dental Hospital, Wonkwang University, who had natural dentition with healthy interdental papillae, and who underwent cone-beam CT were selected. The cone-beam CT images were converted to digital imaging and communication in medicine (DICOM) files and reconstructed in three-dimensional images. To standardize the cone-beam CT images, head reorientation was performed. All of the measurements were determined on the reconstructed panoramic images by three professionally trained dentists. Results: At the CEJ, the mean maxillary interdental distances were $1.84 \mathrm{~mm}$ (anterior teeth), 2.07 $\mathrm{mm}$ (premolar), and $2.08 \mathrm{~mm}$ (molar), and the mean mandibular interproximal distances were $1.55 \mathrm{~mm}$ (anterior teeth), $2.20 \mathrm{~mm}$ (premolar), and $2.36 \mathrm{~mm}$ (molar). At $2 \mathrm{~mm}$ below the CEJ, the mean maxillary interdental distances were $2.19 \mathrm{~mm}$ (anterior teeth), $2.51 \mathrm{~mm}$ (premolar), and $2.60 \mathrm{~mm}$ (molar), and the mean mandibular interproximal distances were $1.86 \mathrm{~mm}$ (anterior teeth), 2.53 $\mathrm{mm}$ (premolar), and $3.01 \mathrm{~mm}$ (molar). Conclusion: The interdental distances in the natural dentition were larger at the posterior teeth than at the anterior teeth and also at $2 \mathrm{~mm}$ below the CEJ level compared with at the CEJ level. The distances between mandibular incisors were the narrowest and the distances between mandibular molars were the widest in the entire dentition. (J Dent Rehabil Appl Sci 2017;33(4):278-83)

Key words: natural dentition; interdental distance; cone-beam computerized tomography; ideal implant positioning

\begin{abstract}
서론
보철치료 후, 건강한 치은과 치간유두 재생 및 유지는 심미적으로나 기능적으로 매우 중요한 고려사항 중의 하 나이다. 특히 치근을 대신하는 임플란트는 새로운 치간 거리를 형성하기 때문에 적절한 치아-임플란트, 임플란 트-임플란트간 거리 유지는 성공적인 임플란트 보철 치 료에 매우 중요하다. ${ }^{1-7}$
\end{abstract}

*Correspondence to: Sang-Chun Oh

Professor, Department of Prosthodontics, College of Dentistry, Wonkwang

University, 77 Doonsan-ro, Seo-gu, Daejeon, 35233, Republic of Korea

Tel: +82-42-366-1100, Fax: +82-42-366-1115, E-mail: scoh@wku.ac.kr

Received: September 7, 2017/Last Revision: November 4, 2017/Accepted:

November 20, 2017
일반적으로 치아 형태 및 배열에 대한 지식은 Black, ${ }^{8}$ Wheeler ${ }^{9}$ 등 많은 연구자들 ${ }^{10}$ 에 의해서 이미 오래 전에 정 립되었고, 치간유두와 관련된 치경부 치은공극(gingival embrasure)에 대한 기술은 많았지만 각 치아의 치간거리 에 대한 구체적인 자료는 부족하였다. 아마 당시는 임플 란트처럼 치간거리에 영향을 주는 치료가 없었기 때문에 임상적 관심이 부족했던 원인으로 판단된다.

최근에는 치간유두와 관련하여 임플란트 이상적인 식

Copyright@ 2017 The Korean Academy of Stomatognathic Function and Occlusion. (c) It is identical to Creative Commons Non-Commercial License. 
립 위치를 찾기 위해 치아-임플란트, 임플란트-임플란트간 수평적 거리에 대한 많은 연구들이 보고되고 있으나, ${ }^{1-7}$ 상 대적으로 자연 치열에 대한 자료가 부족하기 때문에 상 호 비교 연구와 고찰은 드물다.

보철치료의 궁극적 목표는 기능과 심미가 회복될 수 있도록 자연 치아 및 치열을 자연스럽게 완벽히 모조 (mimicry)하는 것이다. ${ }^{11}$ 따라서 필연적으로 치간거리를 재형성 시켜야 하는 임플란트 치료 성공을 위해서 모조 의 대상인 자연 치열의 치간거리에 대한 정확한 정보가 반드시 필요하다. 본 연구의 목적은 이를 위해 CBCT를 이용하여 백악-법랑 경계와 치조골 흡수를 가정한 그 2 $\mathrm{mm}$ 하방에서 자연 치열의 치간거리를 계측하는 것이고, 향후 이런 연구들을 통해 궁극적으로 임플란트의 이상적 인 근원심적 식립 위치와 치관 형태를 정하는데 도움을 주고자 하는 것이다.

\section{연구 재료 및 방법}

원광대학교 치과병원에서 cone-beam CT (PaX-Zenith 3D; Vatech Korea Co., Ltd., Seoul, Korea)를 촬영한 건 강한 치간유두와 치열을 가진 환자를 대상으로 아래의 결격 사유가 없는 200명(남성 100명, 여성 100명)을 선 정하였다. 본 연구는 원광대학교 대전치과병원 IRB심사 (IRB No. W1412/003-001)를 거쳐 진행되었다.

배제 요인:

1. Cone-beam CT 상에 금속 산란을 일으키는 보철치 료를 받은 환자

2. 제 3 대구치 이외에 선천적 또는 후천적으로 상실된 치아가 있는 환자
3. 치조골 흡수 같은 치주질환이 있는 환자

4. 측정이 곤란한 부정교합이 있는 환자

5. 골대사에 영향을 줄 질환이나 치료를 받았던 환자

6. 측정이 곤란할 정도로 불량한 화질의 CBCT 이미지 의 환자

Cone-beam CT는 다음 조건에서 촬영되었다: 105 $\mathrm{kVp}, 6.2 \mathrm{mAs}, 15-24-\mathrm{s}$ scan time, $0.2-$ and $0.3-\mathrm{mm}$ voxel sizes, and $16 \mathrm{~cm} \times 14 \mathrm{~cm}$ field of view. 이미지는 DICOM (digital imaging and communication in medicine) 파일로 저장되었고, DICOM파일은 이미지 소프트 웨어(Ez3D Plus, ver. 1.2.6.7; Vatech Spain, Barcelona, Spain)에서 3차원 영상으로 재구성되었다. Cone-beam CT 이미지를 표준화하기 위해서 두부 재배향(head reorientation)을 시행하였고, 이를 위해 위치표지(position indicator)를 세팅한 후, 커서의 수직선을 축영상(axial view)에서는 구개평면선(palatal plane line)에, 관상영상 (coronal view)에서는 비중격(nasal septum)에 맞추었으 며, 수평선을 구개평면(palatal plane)과 평행하도록 하였 다(Fig. 1A).

축영상에서 소프트웨어의 파노라마 곡선 탭(panoramic curve tab)을 선택하였으며, 모든 치근의 중심을 클릭 함으로써 재구성된 파노라마 이미지(reconstructed panoramic image)상에서 각 치아의 치관, 백악-법랑 경계부, 치조골 등의 최적 이미지를 위해 $1 \mathrm{~mm}$ 간격으로 앞뒤로 움직이며 조정하였다(Fig. 1B).

모든 계측은 이 재구성된 파노라마 이미지 상에서 시 행되었으며, 전치부와 구치부의 적절한 파노라마 커브 (panoramic curve)가 다르기 때문에 전치부와 구치부를 나누어 계측하였다(Fig. 2). 각 악궁을 전치(중절치(I1)-중
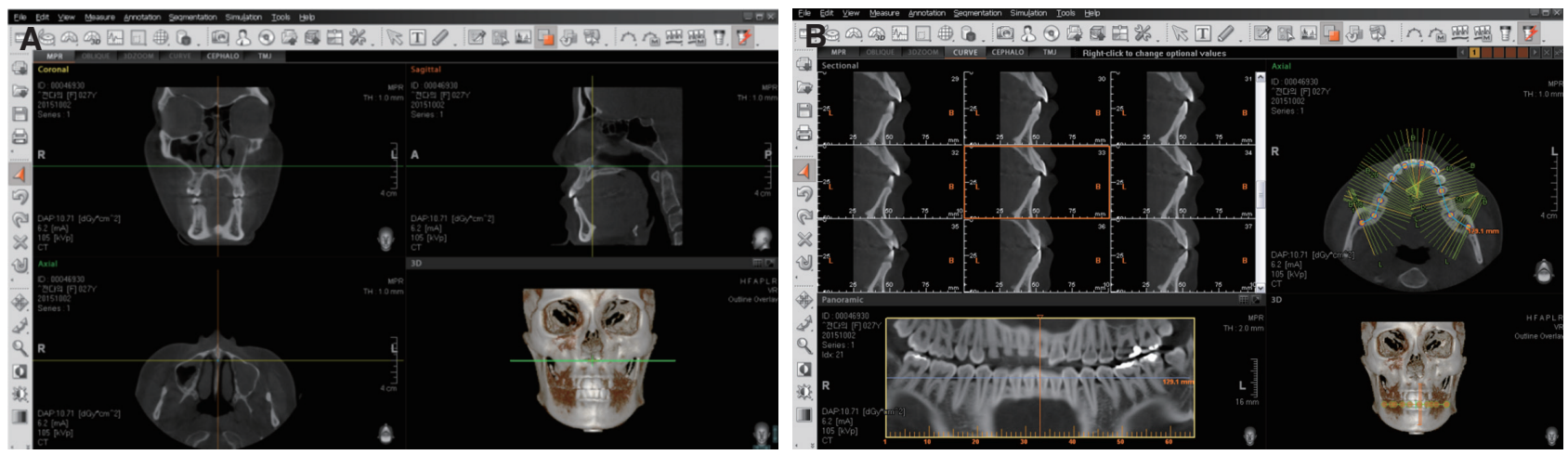

Fig. 1. Standardization of the $C B C T$ images. (A) Reorientation of $C B C T$ image, (B) Making panoramic image: sectional image for measuring. 

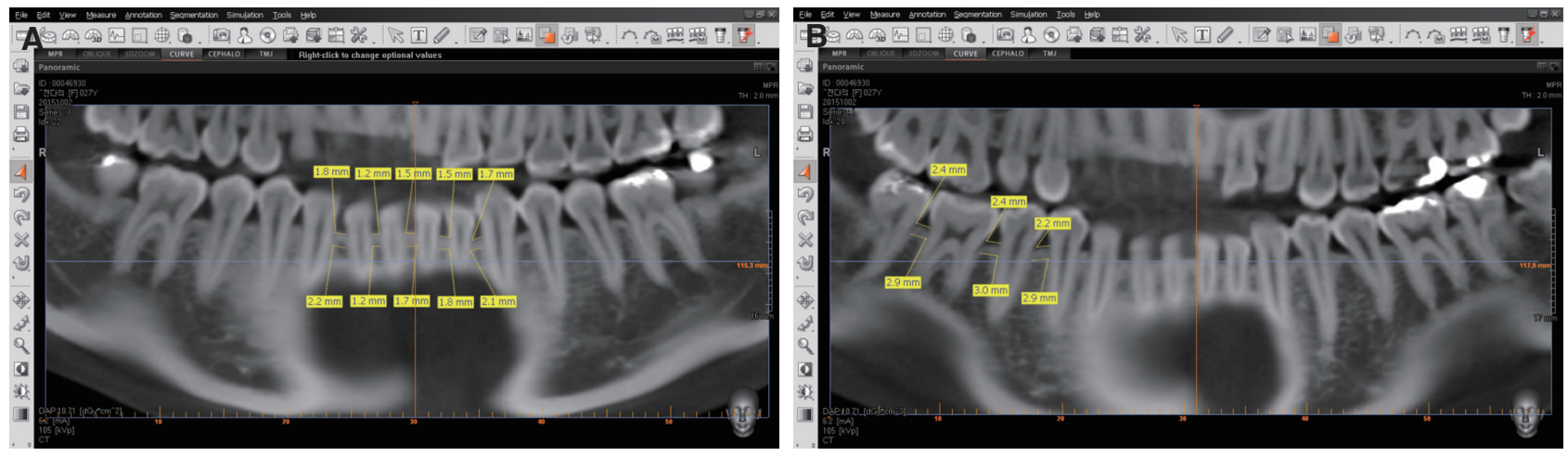

Fig. 2. Measuring distance between adjacent teeth on panoramic view. (A) Anterior teeth, (B) Posterior teeth.

절치(I1), 중절치(I1)-측절치(I2), 측절치(I2)-견치(C)), 소 구치(견치(C)-제1소구치(P1), 제1소구치(P1)-제2소구치 (P2)), 대구치(제2소구치(P2)-제1대구치(M1), 제1대구치 (M1)-제2대구치(M2)) 등으로 나누어 계측하였고, 모든 계측은 3 명의 숙련된 치과의사에 의해서 수행되었다.

통계분석을 위해서 SPSS Version 23 (SPSS Inc., Chicago, USA)를 사용하여 각 치아에서 백악-법랑 경계와 그 하방 $2 \mathrm{~mm}$ 의 치간거리를 비교하기 위해서 independent t-test를 시행하였고, 백악-법랑 경계와 그 하방 2 $\mathrm{mm}$ 로 나누어 각 치아들 간의 치간거리를 비교하기 위해 one-way ANOVA를 시행했으며, 사후 검증은 Scheffetest를 사용하였다.

Table 1. Mean values and standard deviation (SD) of interproximal distance (in $\mathrm{mm}$ ) at CEJ

\begin{tabular}{llll}
\hline \multicolumn{1}{c}{ Teeth } & & Mean & SD \\
\hline \multirow{3}{*}{ Maxillary incisor } & I1-I1 & 1.96 & .526 \\
& I1-I2 & 1.71 & .578 \\
& I2-C & 1.85 & .588 \\
Maxillary premolar & C-P1 & 2.02 & .622 \\
& P1-P2 & 2.12 & .407 \\
Maxillary molar & P2-M1 & 2.21 & .426 \\
& M1-M2 & 1.97 & .390 \\
Mandibular incisor & I1-I1 & 1.53 & .455 \\
& I1-I2 & 1.48 & .474 \\
Mandibular premolar & 1.64 & .589 \\
& C-P1 & 2.02 & .774 \\
Mandibular molar & P2-M1 & 2.38 & .572 \\
& M1-M2 & 2.37 & .499 \\
\hline
\end{tabular}

I1: Central incisor, I2: Lateral incisor, C: Canine, P1: First premolar, P2: Second premolar, M1: First molar, M2: Second molar.

\section{결과}

백악-법랑 경계와 백악-법랑 경계 하방 $2 \mathrm{~mm}$ 에서 상 악과 하악 각 치아의 평균 치간거리를 측정한결과는 Table 1, 2와 같다. One-way ANOVA 분석 결과, 백악-법 랑 경계에서 상악소구치, 하악소구치, 상악대구치 간에 유의한 차이는 없었으나, 이들과 하악전치, 상악전치, 하 악대구치들 간에는 유의한 차이를 보였으며(Table 3). 백 악-법랑 경계 하방 $2 \mathrm{~mm}$ 에서 상악소구치, 하악소구치, 상악대구치 간에 유의한 차이는 없었으나, 이들과 하악 전치, 상악전치, 하악대구치들 간에는 유의한 차이를 보 였다(Table 4). 또한 각 치아의 백악-법랑 경계부와 그 하

Table 2. Mean values and standard deviation (SD) of interproximal distance (in $\mathrm{mm}$ ) at $2 \mathrm{~mm}$ below CEJ

\begin{tabular}{llll}
\hline \multicolumn{1}{c}{ Teeth } & & Mean & SD \\
\hline \multirow{3}{*}{ Maxillary incisor } & I1-I1 & 2.18 & .574 \\
& I1-I2 & 2.06 & .586 \\
& I2-C & 2.33 & .613 \\
Maxillary premolar & C-P1 & 2.46 & .600 \\
& P1-P2 & 2.55 & .485 \\
Maxillary molar & P2-M1 & 2.76 & .508 \\
& M1-M2 & 2.45 & .478 \\
Mandibular incisor & I1-I1 & 1.79 & .499 \\
& I1-I2 & 1.73 & .594 \\
Mandibular premolar C-P1 & 2.05 & .683 \\
& P1-P2 & 2.31 & .780 \\
Mandibular molar & P2-M1 & 2.74 & .642 \\
& M1-M2 & 3.02 & .520 \\
\end{tabular}

I1: Central incisor, I2: Lateral incisor, C: Canine, P1: First premolar, P2: Second premolar, M1: First molar, M2: Second molar. 
Table 3. One-way ANOVA for evaluation of interproximal distance (in $\mathrm{mm}$ ) at $\mathrm{CEJ}$

\begin{tabular}{ll}
\hline \multicolumn{1}{c}{ Teeth } & Mean \pm SD \\
\hline Maxillary incisor & $1.84 \pm 0.467^{\mathrm{a}}$ \\
Maxillary premolar & $2.00 \pm 0.397^{\mathrm{b}}$ \\
Maxillary molar & $2.08 \pm 0.319^{\mathrm{b}}$ \\
Mandibular incisor & $1.50 \pm 0.425^{\mathrm{c}}$ \\
Mandibular premolar & $2.20 \pm 0.493^{\mathrm{b}}$ \\
Mandibular molar & $2.30 \pm 0.412^{\mathrm{d}}$ \\
\hline
\end{tabular}

The same superscripted letters indicate the values that are not significantly different $(P>.01)$.
Table 4. One-way ANOVA for evaluation of interproximal distance (in $\mathrm{mm}$ ) at $2 \mathrm{~mm}$ below CEJ

\begin{tabular}{ll}
\hline \multicolumn{1}{c}{ Teeth } & Mean \pm SD \\
\hline Maxillary incisor & $2.19 \pm 0.529^{\mathrm{a}}$ \\
Maxillary premolar & $2.51 \pm 0.413^{\mathrm{b}}$ \\
Maxillary molar & $2.60 \pm 0.402^{\mathrm{b}}$ \\
Mandibular incisor & $1.86 \pm 0.500^{\mathrm{c}}$ \\
Mandibular premolar & $2.53 \pm 0.582^{\mathrm{b}}$ \\
Mandibular molar & $3.01 \pm 0.445^{\mathrm{d}}$ \\
\hline
\end{tabular}

The same superscripted letters indicate the values that are not significantly different $(P>.01)$.

Table 5. Independent t-test for differences of interproximal distance (in $\mathrm{mm}$ ) between CEJ and $2 \mathrm{~mm}$ below CEJ

\begin{tabular}{lllllll}
\hline \multicolumn{1}{c}{ Teeth } & \multicolumn{2}{c}{ At CEJ } & \multicolumn{2}{c}{ At 2 mm below CEJ } & \multirow{2}{*}{ t } & $P$ \\
\hline Maxillary incisor & 1.84 & .467 & 2.19 & .529 & -7.117 & $.000^{*}$ \\
Maxillary premolar & 2.07 & .397 & 2.51 & .413 & -10.748 & $.000^{*}$ \\
Maxillary molar & 2.08 & .319 & 2.60 & .402 & -14.355 & $.000^{*}$ \\
Mandibular incisor & 1.55 & .425 & 1.86 & .500 & -6.513 & $.000^{*}$ \\
Mandibular premolar & 2.20 & .493 & 2.53 & .582 & -6.206 & $.000^{*}$ \\
Mandibular molar & 2.36 & .412 & 3.01 & .445 & -14.934 & $.000^{*}$ \\
\hline
\end{tabular}

$*: P<.01$

방 $2 \mathrm{~mm}$ 에서 치간거리를 비교한 independent t-test 결 과, 모든 치아에서 백악-법랑 경계보다 그 하방 $2 \mathrm{~mm}$ 에 서 더 넓게 나타났다(Table 5).

\section{고찰}

Cone-beam CT는 두경부에서 해부학적 구조물을 계 측 평가할 수 있는 유용한 치과방사선 장비 중의 하나로, 전용 소프트웨어를 통해서 만들어진 변형이나 확대없는 curved planar reformation된 파노라마 이미지 상에서 선 상 계측(linear measurement)이 가능하며, 이 측정값은 임상적으로 받아 드려질 만큼 정확성이 있는 것으로 보 고된다. ${ }^{12,13}$

$\mathrm{Black}^{8}$ 은 건강한 악궁에서 좌우 제3대구치 원심면 간 거리를 $127 \mathrm{~mm}$, 각 치아의 치경부 근원심 거리의 합 을 $89 \mathrm{~mm}$ 로 보고하였다. 이는 치경부 치간거리의 총합 이 약 $38 \mathrm{~mm}$ 임을 의미하며, 이는 본 연구의 결과(상악: $29.66 \mathrm{~mm}$, 하악: $30.45 \mathrm{~mm}$ )보다 다소 크나, 제 3 대구치 가 포함된 수치임을 감안하면 비교적 유사한 것으로 사 료되었다. 또한 치경부 치간거리가 전치부에서는 중절치 사이, 전 치열에서는 대구치 사이가 가장 컸다고 보고하
면서 구체적인 치아 명이 없었으나, 본 연구 결과를 바탕 으로 전치부에서는 상악중절치 사이, 전 치열에서는 하 악대구치 사이인 것으로 추론 되었다.

Lee 등 ${ }^{14}$ 은 교정용 미니스크루를 안전하게 식립하기 위 해서 CT 상에서 치근간 거리를 측정하였다. 그 중 백악법랑 경계 $2 \mathrm{~mm}$ 하방에서 상악 구치부 구개측 치근간거 리를 P1-P2: $2.42 \pm 0.52 \mathrm{~mm}, \mathrm{P} 2-\mathrm{M} 1: 2.76 \pm 0.67 \mathrm{~mm}$ 그리고 M1-M2: $2.46 \pm 0.78 \mathrm{~mm}$ 인 것으로 보고하였는 데, 이는 본 연구의 결과(P1-P2: $2.55 \pm 0.43 \mathrm{~mm}, \mathrm{P} 2-$ M1: $2.76 \pm 0.46 \mathrm{~mm}, \mathrm{M} 1-\mathrm{M} 2: 2.45 \pm 0.43 \mathrm{~mm}$ )와 매우 유사하여, 두 연구의 높은 신뢰도를 보여주었다.

본 연구는 백악-법랑 경계와 치조골 흡수를 가상한 2 $\mathrm{mm}$ 하방에서 전 치아를 전치, 소구치, 그리고 대구치로 나누어 비교적 상세히 보고함으로써 임플란트의 이상적 인 근원심적 식립 위치를 결정하는데 임상적인 도움을 줄 것으로 사료된다. 그간 임플란트 식립후 치조골의 협설 측과 근원심측 거리는 골개조(bone remodeling)에 영향 을 주는 중요한 요소이고, 이를 위한 최소한의 거리를 제 시하는 임상 가이드라인(협측 두께: $2.0 \mathrm{~mm}$, 치아-임플 란트간 거리: $1.5 \mathrm{~mm}$, 임플란트간 거리: $3.0 \mathrm{~mm}$ )이 제시 되어 왔다. ${ }^{2}$ 그러나 구체적인 치아 위치와 치조골 흡수 조 
건이 제시되지 않아 다양한 환경에 노출되는 임상에서 이를 일괄적으로 적용하기엔 무리가 있다고 판단하였다. 본 연구 결과처럼 전치부와 구치부 그리고 치조골 흡수 에 따른 높이 차에 따라 치간거리가 달라지므로 이를 반 영한 다양한 임상 가이드라인이 최적의 임플란트 식립을 위해 필요할 것으로 사료된다.

\section{결론}

자연치열에서 치간거리는 전치부보다는 구치부에서 더 컸으며, 백악-법랑 경계부보다 그 하방 $2 \mathrm{~mm}$ 에서 더 크게 나타났다. 전 치열에서 가장 좁은 곳은 하악 전치, 가장 넓은 곳은 하악 대구치였다. 따라서 이 제한된 연구 에 근거하면 최적의 임플란트 근원심적 식립 위치를 결정 할 때, 식립 치아와 치조골 흡수 상태를 고려함이 바람직 할 것이다.

\section{Acknowledgements}

This paper was supported by Wonkwang University in 2016.

\section{ORCID}

Sang-Chun Oh https://orcid.org/0000-0001-5496-126X Hyun-Jun Kong https://orcid.org/0000-0001-9331-3572

Wan Lee https://orcid.org/0000-0002-3140-0563

\section{References}

1. Tarnow DP, Cho SC, Wallace SS. The effect of inter-implant distance on the height of inter-implant bone crest. J Periodontol 2000;71:546-9.

2. Gastaldo JF, Cury PR, Sendyk WR. Effect of the vertical and horizontal distances between adjacent implants and between a tooth and an implant on the incidence of interproximal papilla. J Periodontol 2004;75:1242-6.

3. Buser D, Martin W, Belser UC. Optimizing esthetics for implant restorations in the anterior maxilla: anatomic and surgical considerations. Int J Oral Maxillofac Implants 2004;19:43-61.
4. Grunder U, Gracis S, Capelli M. Influence of the 3-D bone-to-implant relationship on esthetics. Int J Periodontics Restorative Dent 2005;25:113-9.

5. Cho HS, Jang HS, Kim DK, Park JC, Kim HJ, Choi SH, Kim CK, Kim BO. The effects of interproximal distance between roots on the existence of interdental papillae according to the distance from the contact point to the alveolar crest. J Periodontol 2006;77:1651-7.

6. Degidi M, Novaes AB Jr, Nardi D, Piattelli A. Outcome analysis of immediately placed, immediately restored implants in the esthetic area: the clinical relevance of different interimplant distances. J Periodontol 2008;79:1056-61.

7. Teughels W, Merheb J, Quirynen M. Critical horizontal dimensions of interproximal and buccal bone around implants for optimal aesthetic outcomes: a systematic review. Clin Oral Implants Res 2009;20:134-45.

8. Black GV. Descriptive anatomy of the human teeth. 5th ed. Philadelphia; S. S. White Dental Manufacturing; 1902. p. 1-94.

9. Wheeler RC. Complete crown form and the periodontium. J Prosthet Dent 1961;11:722-34.

10. Renner RP. An introduction to dental anatomy and esthetics. 1st ed. Chicago; Quintessence; 1985. p. 49-86.

11. Magne P, Belser U. Bonded porcelain restorations in the anterior dentition: a biomimetic approach. 1st ed. Chicago; Quintessence; 2002. p. 50-3.

12. Ganguly R, Ruprecht A, Vincent S, Hellstein J, Timmons S, Qian F. Accuracy of linear measurement in the Galileos cone-beam computed tomography under simulated clinical conditions. Dentomaxillofac Radiol 2011;40:299-305.

13. Hekmatian E, Jafari-Pozve N, Khorrami L. The effect of voxel size on the measurement of mandibular thickness in cone-beam computed tomography. Dent Res J (Isfahan) 2014;11:544-8.

14. Lee KJ, Joo E, Kim KD, Lee JS, Park YC, Yu HS. Computed tomographic analysis of tooth-bearing alveolar bone for orthodontic miniscrew placement. Am J Orthod Dentofacial Orthop 2009;135:48694. 


\section{콘빔형 전산화단층영상을 이용한 자연치 치간거리의 평가}

\section{오상천 ${ }^{1 *}$, 공현준 ${ }^{1}$, 이완 ${ }^{2}$}

${ }^{1}$ 원광대학교 치과대학 치과보철학교실

${ }^{2}$ 원광대학교 치과대학 구강악안면방사선학교실

목적: 본 연구 목적은 이상적인 임플란트 근원심적 식립 위치 결정에 필요한 정보를 제공하기 위해서 콘빔형 전산화단층 영상(cone-beam CT)을 사용하여 건강한 자연치열에서 백악-법랑 경계부와 치조골 흡수를 가정한 그 하방 $2 \mathrm{~mm}$ 에서 전 치, 소구치, 대구치의 치간거리를 평가하는 것이다.

연구 재료 및 방법: 원광대학교 치과대학병원에서 cone-beam CT를 촬영한 건강한 치열의 200명 환자를 선정하였다. Cone-beam CT 이미지를 DICOM (digital imaging and communication in medicine) 파일로 전환하여, 3차원 영상으로 재구성하였고, cone-beam CT 이미지를 표준화하기 위하여 head reorientation을 시행한 후, 전용 소프트웨어를 이용해 재구성된 파노라마 이미지를 얻었다. 모든 계측은 3명의 치과의사에 의해 최적화된 파노라마 이미지 상에서 시행되었다. 결과: 백악-법랑 경계부에서 상악 평균 치간거리는 전치 $1.84 \mathrm{~mm}$, 소구치 $2.07 \mathrm{~mm}$, 대구치 $2.08 \mathrm{~mm}$ 그리고 하악은 전 치 $1.55 \mathrm{~mm}$, 소구치 $2.20 \mathrm{~mm}$, 대구치 $2.36 \mathrm{~mm}$ 였다. 백악-법랑 경계부 하방 $2 \mathrm{~mm}$ 에서 상악 평균 치간거리는 전치 2.19 $\mathrm{mm}$, 소구치 $2.51 \mathrm{~mm}$, 대구치 $2.60 \mathrm{~mm}$ 그리고 하악은 전치 $1.86 \mathrm{~mm}$, 소구치 $2.53 \mathrm{~mm}$, 대구치 $3.01 \mathrm{~mm}$ 였다.

결론: 자연치열에서 치간거리는 전치부보다는 구치부에서 더 컸으며, 백악-법랑 경계부보다 그 하방 $2 \mathrm{~mm}$ 에서 더 크게 나타났다. 전 치열에서 가장 좁은 곳은 하악 전치, 가장 넓은 곳은 하악 대구치였다.

(구강회복응용과학지 2017;33(4):278-83)

주요어: 자연치열; 치간거리; cone-beam CT; 이상적인 임플란트 식립위치

*교신저자: 오상천

(35233) 대전광역시 서구 둔산로 77 원광대학교 대전치과병원 치과보철과

Tel: 042-366-1100 | Fax: 042-366-1115 | E-mail: scoh@wku.ac.kr

접수일: 2017년 9월 7일 | 수정일: 2017년 11월 4일 | 채택일: 2017년 11월 20일 